\title{
BOUNDARY BLOW-UP RATES OF LARGE SOLUTIONS FOR QUASILINEAR ELLIPTIC EQUATIONS WITH CONVENTION TERMS
}

\author{
JING MO AND ZUODONG YANG
}

Abstract. We use Karamata regular variation theory to study the exact asymptotic behavior of large solutions near the boundary to a class of quasilinear elliptic equations with convection terms

$$
\begin{cases}\Delta_{p} u \pm|\nabla u|^{q(p-1)}=b(x) f(u), & x \in \Omega, \\ u(x)=+\infty, & x \in \partial \Omega,\end{cases}
$$

where $\Omega$ is a smooth bounded domain in $\mathbb{R}^{\mathbb{N}}$. The weight function $b(x)$ is a non-negative continuous function in the domain, $f(u) \in C^{2}[0,+\infty)$ is increasing on $[0, \infty)$, and regularly varying at infinity with index $\rho>p-1$.

Mathematics subject classification (2010): 35J25, 35J40, 35J92.

Keywords and phrases: elliptic equation, regular variation, large solutions, boundary blow-up rate, convection terms.

\section{REFERENCES}

[1] C. BANDle AND E. Giarrusso, Boundary blow-up for semilinear elliptic equations with nonlinear gradient terms, Adv. Differ. Eq., 1 (1996), 133-150.

[2] C. Bandle AND M. Marcus, Large solutions of semilinear elliptic equations: Existence, uniqueness and asymptotic behaviour, J. Anal. Math., 58 (1992), 9-24, doi:10.1007/BF02790355.

[3] L. BieberbaCH, $\Delta u=e^{u}$ und die automorphen funktionen, Math. Ann., 77 (1916), 173-212.

[4] N.H. Bingham, C.M. Goldie And J.L. Teugels, Regular Variation, vol. 1, Cambridge University Press, 1987.

[5] K.S. CHENG AND W.M. NI, On the structure of the conformal scalar curvature equation on $\mathbb{R}^{\mathbb{N}}$, Indiana Univ. Math. J., 41 (1992), 261-278, doi:10.1512/iumj.1992.41.41015.

[6] F.C. CîRSTEA, Elliptic equations with competing rapidly varying nonlinearities and boundary blowup, Adv. Differ.Eq., 12 (2007), 995-1030.

[7] F.C. CîRSTEA AND V. RÂDULESCU, Uniqueness of the blow-up boundary solution of logistic equations with absorption, C. R. Acad. Sci. Paris. Ser., I 335 (2002), 447-452, doi:10.1016/S1631073X(02)02503-7.

[8] F.C. CÎRSTEA AND V.RÂDULESCU, Boundary blow-up in nonlinear elliptic equations of BieberbachRademacher type, Trans. Amer. Math. Soc., 359, 7 (2007), 3275-3286, doi:10.1090/S0002-9947-0704107-4.

[9] F.C. CîRSTEA AND V. RÂDUlesCU, Nonlinear problems with boundary blow-up: A Karamata regular variation theory approach, Asymptotic Anal., 46 (2006), 275-298.

[10] F.C. CÎRSTEA AND V. RÂDUlescu, Extremal singular solutions for degenerate logistictype equation in anisotropic media, C. R. Acad. Sci. Paris, Ser.I. 339 (2004), 119-124, doi:10.1016/j.crma.2004.04.025.

[11] F.C. CÎRSTEA AND V. RÂDUlESCU, Existence and uniqueness of blow-up solutions for a class of logistic equation, Commun. Contemp. Math., 4 (2002), 559-586.

[12] Y. DU AND Z. GUO, Boundary blow-up solutions and their applications in quasilinear elliptic equations, J. Anal. Math., 89 (2003), 277-302, doi:10.1007/BF02893084. 
[13] F. Gladiali and G. Porru, Estimates for explosive solutions to p-Laplace equations, Progress in Partial Differential Equations, Pont-Mousson, 1 (1997), in: Pitman Res. Notes Math. Ser., 383, Longman,Harlow, 1998, 117-127.

[14] J.L. GómEZ, Optimal uniqueness theorems and exact blow-up rates of large solutions, J. Differ. Eq., 224 (2006), 385-439, doi:10.1016/j.jde.2005.08.008.

[15] S.B. HUANG AND Q.Y. TIAN, Boundary blow-up rates of large solutions for elliptic equations with convection terms, J. Math.Anal. Appl., 373 (2011), 30-43, doi:10.1016/j.jmaa.2010.06.031.

[16] J. Karamata and Jovan, Sur un mode de croissance reguliere des fonctions, Mathematica, 4 (1930), 38-53.

[17] J. Karamata, Sur un mode de croissance rêguliere thêoremes fondamentaux, Bull. Soc. Math., France, 61 (1933), 55-62.

[18] J.B. Keller, On solutions of $\Delta u=f(u)$, Comm. Pure. Appl. Math., 10 (1957), 503-510, doi:10.1002/cpa.3160100402.

[19] A.C. LAZER And P.J. MCKenna, On a problem of Bieberbach and Rademacher, Nonlinear Anal., 21 (1993), 327-335, doi:10.1016/0362-546X(93)90076-5.

[20] C. Loewner And L. Nirenberg, Partial Differential Equations Invariant under Conformal or Projective Transformations, Contrib. Anal., Academic Press, New York, 1974, 245-272.

[21] C.L. LiU AND Z.D. YANG, Boundary blow-up quasilinear elliptic problems of the Bieberbach type with nonlinear gradient terms, Nonlinear Anal., 69 (2008), 4380-4391, doi:10.1016/j.na.2007.10.060.

[22] C.L. LIU AND Z.D. YANG, Existence of large solutions for a quasilinear elliptic problem via explosive sub-supersolutions, Appl. Math. Comput., 199 (2008), 414-424, doi:10.1016/j.amc.2007.10.009.

[23] A. Moнammed, Boundary asymptotic and uniqueness of solutions to the p-Laplacian with infinite boundary values, J. Math. Anal. Appl., 325 (2007), 480-489, doi:10.1016/j.jmaa.2006.02.008.

[24] R. Osserman, On the inequality $\Delta u \geqslant f(u)$, Pacific J. Math., 7 (1957), 1641-1647.

[25] F. PEnG, Remarks on large solutions of a class of semilinear elliptic equations, J. Math. Anal. Appl., 356 (2009), 393-404, doi:10.1016/j.jmaa.2009.03.021.

[26] S.L. Pohozaev, The Dirichlet problem for the equation $\Delta u=u^{2}$, Soviet Math. Dokl., 1 (1960), $1143-1146$.

[27] S.I. Resnick, Extreme Values, Regular Variation, and Point Processes, Springer-Verlag, Berlin, New York, 1987.

[28] E. Seneta, Regularly Varying Functions, Lecture Notes in Math., vol. 508, Springer-Verlag, Berlin, New York, 1976.

[29] Z. ZHANG, The asymptotic behaviour of solutions with blow-up at the boundary for semilinear elliptic problems, J. Math. Anal. Appl., 308 (2005), 532-540, doi:10.1016/j.jmaa.2004.11.029.

[30] Z.J. ZHANG, Y.J. MA, L. MI AND X.H. LI, Blow-up rates of large solutions for elliptic equations, J. Differential Equations, 249 (2010), 180-199, doi:10.1016/j.jde.2010.02.019. 